\title{
EL «VIEJO» LIBERALISMO DE J. S. MILL EN LA CONCEPCIÓN LIBERAL DE ORTEGA Y GASSET
}

\author{
J. S. MILL'S «OLD» LIBERALISM IN THE \\ LIBERAL CONCEPTION OF ORTEGA Y GASSET
}

\author{
Ignacio José SANZ GARCíA* \\ UNED
}

Resumen: Este artículo trata de profundizar en el sentido de la crítica de Ortega y Gasset a las ideas de lo que él mismo llamó «viejo» liberalismo del siglo XIX, que tuvo a John Stuart Mill como su representante más importante. Veremos cómo Ortega parte de algunas de las reflexiones de Mill para elaborar sus concepciones sobre las sociedades de masas. Sin embargo, Ortega intentará formular un liberalismo que se apoye en la historia, rechazando el carácter colectivista que parecen tener las teorías liberales decimonónicas. El modelo para hacer esto será la civilización romana y el señor germano medieval. Busca Ortega así un «nuevo» liberalismo que se construya desde el individuo viviente que moldearía las instituciones políticas con el fin de limitar el poder público. Todo ello motivado por la necesidad de una reforma del liberalismo, dada la crisis europea.

Palabras Clave: «viejo» liberalismo, concordia, colectivismo, progresismo, libertas.

AвSTRACT: This article tries to deepen our understanding of the meaning of Ortega $y$ Gasset's criticism of the ideas of what he called the «old» liberalism of the $19^{\text {th }}$ century, whose most important representative was John Stuart Mill. We will see how Ortega starts with some of Mill's reflections to elaborate his conceptions about mass societies. However, Ortega will try to formulate a liberalism based on history, rejecting the collectivist character that $19^{\text {th }}$ century liberal theories seem to have. The model to do this is Roman civilization and the medieval German lord. In this way, Ortega is looking for a «new» liberalism built around the living individual that would mold political institutions with

\footnotetext{
*Doctor en Filosofía por la UNED. E-mail: Ignacio_sga@yahoo.es.
} 
the purpose of limiting public power. All of this is motivated by the need of a reform of liberalism, given the European crisis.

KeYwORDs: «old» liberalism, concord, colletivism, progressism, libertas.

\section{Introducción}

Se analiza en este artículo la influencia del liberalismo de John Stuart Mill en la concepción liberal de Ortega y Gasset. Veremos como el filósofo madrileño toma muchas de las reflexiones de Mill para formular su diagnóstico sobre las sociedades de masas aunque, a su vez, toma distancias respecto al colectivismo del que, según él, adolecen los liberales decimonónicos -entre ellos Mill-. Desde aquí buscará formular un «nuevo» liberalismo que parta de la historia y que tenga su fundamento en la misma vida humana. La civilización romana y el modo de vida del señor germano medieval serán así los hilos conductores utilizados, la primera para evaluar los males de las sociedades europeas de su tiempo y el segundo para fijar el origen de las libertades clásicamente enumeradas por el liberalismo moderno. Desde estas coordenadas Ortega busca romper con el paradigma progresista, lo que implica partir de una concepción diferente de la historia, no entendida como algo que evoluciona de forma natural a mejor, sino como estructura jerarquizada de las «creencias» que se suceden encadenadas a lo largo del tiempo. Esto implica dotar de una historicidad a ideas como la libertad, lo que en el plano político implicará la posibilidad de una «vida como libertad» en sociedades supuestamente ajenas a las libertades clásicas del liberalismo. La labor del historiador adquiere así un fuerte componente interpretativo con implicaciones políticas, pues es desde la historia desde donde podemos proporcionar a la sociedad ideas para posibilitar una cohesión social básica, una concordia. Subyace a todo este diálogo con los liberales decimonónicos la cuestión de cómo limitar un poder público que se está convirtiendo en una seria amenaza para el individuo en la Europa de Ortega. Sólo se podrá hacer esto construyendo una sociedad en la que la libertad individual venga desde abajo, desde el mismo individuo viviente, e impregne desde ahí las instituciones. Hay que buscar una legitimidad para la ley, que garantiza las libertades formales del liberalismo, que se sitúe más allá de ella, en las mismas «creencias» de la sociedad. 


\section{La crítica orteguiana al colectivismo de fondo del pensamiento liberal del siglo XIX representado por J. S. Mill.}

En La rebelión de las masas lleva a cabo nuestro autor un breve repaso histórico en el que vendrá a resaltar el fundamental carácter colectivista del liberalismo del siglo XIX ${ }^{1}$, que contrasta con un liberalismo individualista que "pertenece a la flora del siglo XVIII» (IV, 125)2. Por extensión Herbert Spencer y John Stuart Mill, como "grandes teorizadores del liberalismo" (IV, 126), no serían sino ilustres representantes de este colectivismo, ya que

su presunta defensa del individuo no se basa en mostrar que la libertad beneficia o interesa a éste, sino todo lo contrario, en que beneficia e interesa a la sociedad. [...] El famoso «individualismo» de Spencer boxea continuamente dentro de la atmósfera colectivista de su sociología. Resulta, a la postre, que tanto él como Stuart Mill tratan a los individuos con la misma crueldad socializante que los termites a ciertos de sus congéneres, a los cuales ceban para chuparles luego la sustancia. ¡Hasta ese punto era la primacía de lo colectivo el fondo por sí mismo evidente sobre que ingenuamente danzaban sus ideas! [...] El descubrimiento -sin duda glorioso y esencial- de lo social, de lo colectivo, era demasiado reciente. Aquellos hombres palpaban, más que veían, el hecho de que la colectividad es una realidad distinta de los individuos y de su simple suma, pero no sabían bien en qué consistía y cuáles eran sus efectivos atributos. [...] De aquí que los «viejos liberales» se abriesen sin suficientes precauciones al colectivismo que respiraban. Mas cuando se ha visto con claridad lo que en el fenómeno social, en el hecho colectivo, simplemente y como tal, hay por una lado de benéfico, pero, por otro, de terrible, de pavoroso, sólo puede uno adherir a un liberalismo de estilo radicalmente nuevo, menos ingenuo y de más diestra beligerancia $[\ldots]$ (IV, 126-127).

\footnotetext{
${ }^{1}$ Para F. López Frías (1992), «la creación característica del siglo XIX ha sido el colectivismo, idea de origen francés que aparece por primera vez en los archirreaccionarios De Bonald y De Maistre. [...] El colectivismo triunfa con Saint-Simon, Ballanche y Comte, extendiéndose por todas partes hasta el extremo de que incluso los alemanes pretendieron haber sido los descubridores de lo social como una realidad distinta de los individuos y "anterior" a éstos», (p. 139).

2 Para mayor claridad las citas de Ortega van con el número en romanos del volumen de las obras completas seguido del número de página.
} 
Será en Del imperio romano ${ }^{3}$ donde Ortega siente las bases de un «nuevo» liberalismo "menos ingenuo», un liberalismo que requiere de un marco legal previo, pero sobre todo de una "creencia» en la libertad individual que legitime unas instituciones de estilo liberal y mantenga la concordia social ${ }^{4}$. A estas alturas, ańos 40, nuestro autor no tiene ya duda del hiato existente entre colectividad e individuo, del carácter en muchas ocasiones terrible de la sociedad -la "gran desalmada" 5 -, lejos de ese Estado postulado desde el «espíritu» germano que surgía como cosa secundaria del cruce de relaciones interindividuales entre nnobles» $^{6}$. Por el contrario, la idea de conciliar individuo

${ }^{3}$ Obra publicada en 1941 , a partir de una serie de artículos que salen a la luz el año anterior en La Nación de Buenos Aires.

4 "Creencia» entendida en sentido objetivo, algo con lo el individuo se encuentra, así nos dice Ortega en Historia como sistema (1935) que " lo específico, lo constitutivo de la opinión colectiva es que su existencia no depende de que sea o no aceptada por un individuo determinado. Desde la perspectiva de cada vida individual aparece la creencia pública como si fuera una cosa física», (VI, 19). En Roma "el Senado fue la institución central» (VI, 63); pero este carácter de infalibilidad se apoyará, a su vez, en la «creencia» del hombre romano en «realidades absolutas que pueden más que él», un orden universal que fundamenta las instituciones humanas, lo que sería representado por los «auspicios» (VI, 64). Es la circunstancia socio-histórica la que determina qué «creencias» mantienen la cohesión básica de la sociedad, la «concordia». Se apoya Ortega en Cicerón para realizar estas afirmaciones. Por ejemplo, en Sobre la república se refiere Cicerón a los auspicios y el senado como "estos dos egregios puntales de la república» (II, 10, 17). La idea es que la libertad sólo es posible dentro de una marco legal previo, por lo que el problema es el de legitimar la ley. Esto en Roma lo hacen las «creencias» descritas.

${ }^{5}$ Desde este punto de vista introduce Ortega el concepto de libertas, inspirado de nuevo en Cicerón, un concepto que «no es la libertad o libertades del liberalismo. [...] Protesto contra el agostamiento de la idea de libertad que la doctrina y propaganda liberales han ocasionado. [...] El hecho normal de la historia europea frente a la de Oriente ha sido la vida como libertad. [...] La libertas romana no tiene prácticamente nada que ver con el liberalismo de nuestros abuelos. [...] El vicio original del liberalismo: creer que la sociedad es, por sí y sin más, una cosa bonita que marcha lindamente. [...] La sociedad, lejos de ser una cosa bonita, es una cosa terrible» (VI, 71-72). Véase también El hombre y la gente (curso 1949-50), donde se señala Ortega que «eso del alma colectiva, de la conciencia social es arbitrario misticismo. [...] ¿Entonces será lo característico de la gente, de la sociedad, de la colectividad, precisamente que son desalmadas?» (VII, 199).

${ }^{6}$ En Notas del Vago Estío (1925) encontrará Ortega en el señor germano medieval la inspiración de la libertad individual tal como la conocemos hoy en día, así la figura del castillo se presenta como un símbolo, una metáfora de ese afán de defender lo privado frente a lo público -«sus torres están labradas para defender a la persona contra el Estado» (II, 424). Aquí el Estado se presenta como algo secundario resultado de «un entrecruzamiento de relaciones personales» (II, 421). Desde esta perspectiva se establece la diferencia entre democracia (¿quién debe mandar?) y liberalismo (¿cuánto debe mandar?), es decir la cuestión de los límites del poder público (véase II, 425). 
y sociedad, supuestamente subyacente en los liberales decimonónicos, guarda estrecha relación con la de una humanidad que existe a priori y cuyo progreso sería observable. En este sentido la sociedad europea estaría en la cúspide de la civilización. Ortega, desde la razón «histórica», rechazará que haya una «humanidad» a priori y de un progreso "necesario», pues en las diferentes civilizaciones históricas como "campos históricos inteligibles» -es decir como realidades históricas que se entienden como un «todo» sin necesidad de recurrir a realidades más amplias- se observan fases de «progreso» y «decadencia» (otra cuestión es qué criterios usamos para valorar cuándo una civilización se halla en una u otra fase $)^{7}$. No hay razones para pensar que la sociedad europea liberal- no pueda derrumbarse como lo hicieron otras (véase el caso del imperio romano). Por tanto, desde este punto de vista, entre individuo y sociedad (entendida como conjunto de usos coactivos de mayor o menor intensidad) no hay conciliación posible, hay tensión permanente (al menos en el caso de individuos que han "despertado a la vida personal» y no se dejan arrastrar por las "corrientes de opinión", que son capaces, en definitiva, de volverse hacia sí mismos, de «ensimismarse» ${ }^{8}$ ).

Aquí surge una cuestión interesante, a saber: en el párrafo citado más arriba criticaba Ortega que estos liberales decimonónicos basaran su defensa de la libertad individual en que beneficia a la sociedad y no en que beneficia al individuo. ¿Quiere esto decir que Ortega considera que la libertad individual es «de-por-sí» beneficiosa para el individuo? En otras palabras, ir "contracorriente», no plegarse ante los usos vigentes en ciertos casos, inventar, ofrecer nuevas ideas a la sociedad ¿beneficia al individuo? Si entendemos por «beneficio» el hecho de cumplir nuestra «vocación» se podría contestar afirmativamente, sin embargo sucede que muchas veces este tipo de individuos pueden ser vistos como una amenaza por la sociedad y por ello se les intentará neutralizar o eliminar. Como se ve este planteamiento nos aboca a una especie de «tira y afloja» entre el individuo creador o dotado de «excelencia» y la sociedad. La alternativa a esto

\footnotetext{
${ }^{7}$ No podemos entrar aquí en esta compleja cuestión (Véase al respecto IX, 37 y ss.; en las lecciones de 1948-49, Una interpretación de la historia universal).

${ }^{8}$ Véase en El hombre y la gente, el capítulo I «Ensimismamiento y alteración», VII, 95, donde compara Ortega la situación europea con la de tiempos de Cicerón, en ambas épocas «se perdió -como amenaza perderse en Europa, si no se pone remedio- la capacidad de ensimismarse, de recogernos con serenidad en nuestro fondo insobornable. Se habla sólo de acción. Los demagogos, empresarios de la alteración, que ya han hecho morir a varias civilizaciones, hostigan a los hombres para que no reflexionen, procuran mantenerlos hacinados en muchedumbres para que no puedan reconstruir su persona donde únicamente se reconstruye, que es en soledad».
} 
será una teoría liberal que trata con una "crueldad socializante» a todos los individuos, de forma similar a las «termites», si bien estos animales son incluso más benévolos y sólo llevan a cabo esta cruel «socialización» con algunos de sus congéneres. Obsérvese el detalle de que Ortega está comparando una teoría, la liberal, con un hecho biológico observable en una sociedad animal fuertemente jerarquizada ¿debemos pensar que lo hace por descuido o que más bien es un modo de resaltar el error de una "teoría» nacida de una razón "pura» que pasa por alto el hecho de que el individuo es en último término algo «vivo»? Inclinándonos más bien por lo segundo diríamos que la «crueldad socializante» a la que se refiere Ortega consiste en asignar a todos los individuos un conjunto de libertades formales, olvidando lo que cada uno tiene de diferente, de genuinamente personal. El filósofo español no tiene nada en contra de dotar de unos derechos mínimos, de justicia, a todos los individuos, siempre que a la vez se reconozcan unos derechos máximos, que tienen que ver con la posibilidad real de ser diferente, de vivir una vida auténticamente personal véase Democracia morbosa (1917) (II, 241), donde Ortega habla de «una nueva aristocracia», que dé una nueva estructura a la sociedad, es decir una nueva «jerarquía social» que, se puede deducir, esté basada en la excelencia personal y no en los bienes materiales que cada uno posee (véase II, 241) ${ }^{9}$. En este sentido la crítica a H. Spencer y J. S. Mill se puede entender no como un rechazo de sus teorías liberales sino como el intento de incorporar una determinada idea de «vida humana» para completarlas.

\footnotetext{
${ }^{9}$ Se trata de la cuestión de qué se hace con la libertad, que engarza el liberalismo político de Ortega con su filosofía a través del paradigma del «seńor germano-medieval» y Roma. No es sólo nuestro autor el que ve los retos a los que se enfrentan las sociedades europeas modernas. Añadamos, por su sintonía con los planteamientos orteguianos, los análisis de Erich Fromm en El miedo a la libertad (1941), donde, desde sus coordenadas freudianas, dice cosas como esta: «Olvidamos que, aún cuando debemos defender con el máximo vigor cada una de las libertades obtenidas, el problema de que se trata no es solamente cuantitativo, sino también cualitativo; que no debemos preservar y aumentar las libertades tradicionales, sino que, además, debemos lograr un nuevo tipo de libertad, capaz de permitirnos la realización plena de nuestro propio yo individual, de tener fe en él y en la vida», Buenos Aires, Paidós, p. 115.
} 


\section{La influencia de J. S. Mill en el diagnóstico orteguiano de la evolución de las sociedades de masas. El intento de formulación de un «nuevo» liberalismo desde los paradigmas germano-medieval y romano.}

Ahora bien, otra cosa es si la valoración que hace Ortega de dichos autores es más o menos justa o "exagerada» (sin olvidar que "pensar es exagerar», como sabe bien nuestro autor). Interesa destacar aquí la perspectiva de Rodríguez Hueścar (1979) por hallarse bajo la influencia orteguiana, así en su «Introducción» a Sobre la libertad (obra publicada en 1859) señala que

Mill, en la primera línea de su libro se adelanta a decirnos que no va a tratar del libre albedrío -es decir, de la libertad en sentido ético o metafísico-, sino de «la libertad social o civil». Pero ni siquiera con esta primera restricción deja de ofrecer el término una multitud de significaciones. Y, ante todo, las determinadas por la variación de las condiciones históricas, que hace que no se parezca en casi nada, por ejemplo, la libertad del mundo antiguo (griego o romano), a lo que el hombre moderno ha entendido por tal (véase, sobre este punto, el lúcido examen que Ortega hace de la libertas ciceroniana en $D e l$ Imperio romano y en sus apéndices: Libertas y Vida como libertad y vida como adaptación. Véase también, del mismo Ortega, desde otro aspecto, el sentido de la franquía feuda ${ }^{10}$, origen de la moderna idea liberal, en Ideas de los castillos). Mas, ni aun limitándonos a la noción moderna de libertad cobra la expresión la univocidad deseada (pp. 15-16).

Obsérvese como este autor echa mano de los paradigmas del «germanomedieval» y el «romano» tal como los formula Ortega para mostrarnos la complejidad del concepto de libertad (aunque sólo se trate de la social). Encarnarían ambos dos tipos de libertad con consecuencias socio-políticas, el primero referido a "quién debe mandar» (libertad positiva) y el segundo a los límites de ese mando (libertad negativa). J. S. Mill se va a mover más bien en

\footnotetext{
${ }^{10}$ En efecto, para Ortega «las burguesías occidentales no han hecho más que imitar las maneras inventadas por las viejas aristocracias feudales. Los "derechos del hombre" son franquías y nada más. [...] El germano fue más liberal que demócrata. El mediterráneo, más demócrata que liberal» (II, 426). Sobre los orígenes históricos de estos privilegios señala M. Bloch (2011) que «el señor, mediante un acta auténtica, fijaba las costumbres propias de tal o cual tierra. [...] En Francia, se les llamaba cartas de costumbres, o de franquicias. [...] La carta de costumbre fue, en Europa de los últimos tiempos feudales y del período siguiente, una institución muy general» (pp. 285-287).
} 
este último terreno, su preocupación es cómo limitar un poder público que está mostrando una tendencia peligrosa a coartar las libertades individuales. Preocupación que se extenderá a toda la sociedad ${ }^{11}$ y que tendrá evidente influencia en el diagnóstico orteguiano de La rebelión de las masas ${ }^{12}$. En este sentido señala el autor inglés

La voluntad del pueblo, significa, en realidad, la voluntad de la porción más numerosa y activa del pueblo, de la mayoría, o de aquellos que consiguieron hacerse aceptar como tal mayoría. Por consiguiente, el pueblo puede desear oprimir a una parte de sí mismo, y contra él son tan útiles las precauciones como contra cualquier otro abuso del poder. [...] Por esto es siempre importante conseguir una limitación del poder del gobierno sobre los individuos [...]. La "tiranía de la mayoría» se incluye ya dentro de las especulaciones políticas como uno de esos males contra los de la sociedad debe mantenerse en guardia. [...] La sociedad puede ejecutar, y ejecuta de hecho, sus propios decretos; y si ella dicta decretos imperfectos, o si los dicta a propósito de cosas en que no se debería mezclar, ejerce entonces una tiranía social mucho más formidable que la opresión legal: pues, si bien esta tiranía no tiene a su servicio tan fuertes sanciones, deja, en cambio, menos medios de evasión; pues penetra mucho más a fondo en los detalles de la vida, llegando hasta encadenar el alma. No basta, pues, con una simple protección contra la tiranía del magistrado. Se requiere, además, protección contra la tiranía de las opiniones y pasiones dominantes; contra la tendencia de la sociedad a imponer como reglas de conducta sus ideas y costumbres a los que difieren de ellas, empleando para ello medios que no son precisamente las penas civiles; contra su tendencia a obstruir el desarrollo e impedir, en lo posible, la formación de individualidades diferentes, y a modelar, en fin, los caracteres con el troquel del suyo propio (Mill, 1979, pp. 33-34).

Por tanto se puede hablar de coincidencia entre Mill y Ortega a la hora de delinear el rumbo que están tomando las sociedades modernas. Ambos ven con

\footnotetext{
${ }^{11}$ Señala en su «Introducción» Rodríguez Huéscar (1979) que «todo el libro de Mill es una voz alerta frente a este nuevo y formidable poder que inicia su marcha ascendente, frente a este peligro - la absorción del individuo por la sociedad- que se alza como henchida nube de tormenta sobre el horizonte del mundo civilizado. [...] Mill intuye certeramente $-y$ hasta cree descubrir en ello una especie de ley histórica- el signo creciente de esta absorción, y lo denuncia sin vacilaciones como el nuevo enemigo de la libertad» (p. 19), y también: «La democracia en América, influyó indudablemente en estas ideas de Stuart Mill» (p. 18). De hecho el autor inglés realizó un extenso comentario de tal obra (véase Mill, 1977).

${ }^{12}$ Véase Rodríguez Huéscar (1979, p. 20).
} 
claridad los peligros que acechan al Viejo Continente, otra cosa serán las ideas que aporten para solucionarlos. Por el simple hecho de que Ortega se encuentra inmerso en un estadio del proceso más avanzado tendrá, digamos, más "datos» para completar su diagnóstico y podrá, a su vez, señalar los posibles errores en las teorías de sus predecesores (cosa parecida a la que podrá hacer Raymond Aron con el mismo Ortega cuando analice las sociedades industriales en la época de la Guerra Fría $\left.{ }^{13}\right)$.

Concretamente en el siguiente texto de J. S. Mill (1979) vislumbramos su forma de entender la separación entre individuo y sociedad:

Pero hay una esfera de acción en la que la sociedad, como distinta al individuo, no tiene más que un interés indirecto, si es que tiene alguno. Nos referimos a esa porción de la conducta y de la vida de una persona que no afecta más que al propio sujeto, y que si afecta igualmente a otras, lo hace con su previo consentimiento y con una participación libre, voluntaria y perfectamente clara. Cuando digo que no afecta más que al propio sujeto, me refiero a lo que le atańe inmediatamente y en primera instancia; pues todo lo que afecta a un individuo puede afectar a otro a través de él, y la objeción que se funde en este hecho será objeto de nuestras reflexiones ulteriores. Esta es la esfera propia de la libertad humana. Comprende, en primer lugar, el dominio interno de la conciencia, exigiendo la libertad de conciencia en el sentido más amplío de la palabra, la libertad de pensar y de sentir, la libertad absoluta de opiniones y de sentimientos, sobre cualquier asunto práctico, especulativo, científico, moral o teológico (p. 40).

No se le escapa al autor inglés que individuo y sociedad son realidades distintas, cuestión diferente es determinar la naturaleza de tal separación. En este fragmento se presenta la sociedad más bien como el fondo indeterminado sobre el que se destaca un individuo del que sí tenemos «noticias» procedentes precisamente de su misma introspección. Partimos así de un «dominio interno»,

\footnotetext{
${ }^{13}$ Llega a señalar Aron (2006) que Ortega se equivocó respecto a su valoración de la Unión Soviética ya que, aunque probablemente «habría modificado su juicio acerca del papel del marxismo en la Unión Soviética», "ese papel es completamente diferente del que Ortega le reconocía. Joven o no, Rusia se ha entregado a una ideología que no ha perdido su capacidad de expansión, aunque en Europa occidental parece destinada a una decadencia irresistible»; en cuanto Estados Unidos también "Ortega, al menos en este libro, se equivoca" pues «estimaba a los Estados Unidos demasiado estrechamente utilitarios» (p. 238). Afirmación ciertamente discutible, al menos en el caso de la Unión Soviética, vistos los acontecimientos de 1989, no podemos entrar en esta cuestión aquí.
} 
de una conciencia en la que se basa nuestra libertad y que en principio no tendría valor para la sociedad. Lo que interesa aquí es la proyección socio-política de los elementos que nacen de dicha conciencia, en forma de opiniones o conductas. En este sentido lo único que puede decirse es que Mill está postulando una libertad negativa («exige libertad absoluta» de pensamientos, sentimientos etc...), es decir, unos "derechos mínimos». No aborda en este punto los problemas derivados de ejercer estos derechos en cada situación concreta, aunque sí lo va a hacer, como él mismo dice, en «reflexiones ulteriores».

Aunque Mill no llega a diferenciar aquí con claridad, de forma similar a Ortega, entre el «hecho social» y las relaciones privadas entre sujetos libres (siguiendo el modelo del «señor germano-medieval»" ${ }^{14}$ ), se podría deducir que tiene presente de una forma u otra tal distinción cuando habla de "consentimiento" y "participación libre y voluntaria» entre los individuos que actúan dentro de esta esfera de libertad individual, de hecho cuando enumera el resto de libertades que son necesarias para poder «llamar libre a una sociedad» cuenta «la libertad de asociación de los individuos» entre ellas, siempre que sea para un fin «inofensivo para los demás y con tal que las personas asociadas sean mayores de edad y no se encuentren coaccionadas ni engañadas» (Mill, 1979, p. 41). Imprescindible considerará también «la libertad de organizar nuestra vida siguiendo nuestro modo de ser, de hacer lo que nos plazca, sujetos a las consecuencias de nuestros actos, sin que nuestros semejantes nos lo impidan, en tanto que no les perjudiquemos [...]» (Mill, 1979, p. 41). El criterio principal en el que Mill se apoya para poner límites a estas libertades es que no afecten a los demás o si lo hacen que exista un consentimiento de por medio. Ahora bien, parece evidente que la cuestión está aquí en cómo saber lo que perjudica o afecta a un grupo o a un individuo concreto ${ }^{15}$.

14 Para Ortega, en el pacto entre señores medievales «el hombre se une al hombre por un nexo que queda sepultado en lo más íntimo de ambos» (II, 433). Se trata de una relación de igual a igual, de intimidad a intimidad, por lo que se asemeja a lo que Ortega llamará en $E l$ hombre y la gente, "hechos de convivencia» que no son "por sí mismos hechos sociales. Forman lo que debiera llamarse "compañía o comunicación" - un mundo de relaciones interindividuales» (VII, 75).

15 Señala John Gray (1994) que «en vista de que el proyecto de Mill era el de reconciliar la preocupación utilitaria por el bienestar general con la preocupación liberal acerca de la prioridad y una distribución equitativa de la libertad, dicho proyecto estaba destinado al fracaso, ya que es altamente improbable que una política utilitaria de prevención del daño respetara, en toda ocasión, las constricciones a la equidad en la consecuente distribución de límites a la libertad. [...] En parte, el fracaso del proyecto de Mill ha sido una motivación central en el resurgimiento reciente de enfoques contractualistas en la justificación de los 
Para dilucidar tal problema J. S. Mill (1979) introduce el concepto de «utilidad», que jugará un papel central en su concepción liberal. La «utilidad» es, para empezar, criterio ético «supremo»:

Considero que la utilidad es la instancia suprema de toda cuestión ética, pero debemos entenderla en el sentido más amplio del vocablo, como fundada en los intereses permanentes del hombre en cuanto ente progresivo. Estos intereses, lo sostengo, sólo autorizan a la sumisión de la espontaneidad individual a un control exterior en aquello que se refiere a las acciones de un presunto individuo en relación con los intereses de otro (p. 39).

Este planteamiento nos lleva a preguntar por los «intereses permanentes», por el criterio que hemos de usar para identificarlos. Si bien parece claro que todo gira alrededor de la idea de "progreso", no queda claro, al menos en esta cita, si se trata de "progreso" personal del individuo o de la sociedad o de ambos. Más bien lo último, entendido como un ideal de conciliación de los intereses de la sociedad y los del individuo. En este sentido (ideal) la conducta «ética» del individuo derivaría en una mejora continua de la sociedad.

Tales postulados aparecerán reflejados en las reflexiones históricas del autor inglés, así las civilizaciones antiguas serán vistas como estadios previos de la europea moderna, en la que la idea de libertad individual se habría impuesto plenamente. No falta en Mill la clásica distinción del hombre moderno y el antiguo, muy en la línea de autores como Benjamin Constant ${ }^{16}$, a saber:

Las repúblicas de la antigüedad se creían con derecho (y los filósofos apoyaban su pretensión) de reglamentar toda la conducta humana por medio de la autoridad pública, con el pretexto de que la disciplina física y moral de cada ciudadano era del mayor interés para el Estado. Esta manera de pensar podría ser admisible en las pequeñas repúblicas rodeadas de enemigos

\footnotetext{
principios liberales» (p. 88). Si seguimos a este autor habría que hablar de una doble preocupación en la obra de Mill, por el bienestar general y por la libertad individual, y el fracaso vendría dado porque no pudo conciliar ambas. Esto indica que Gray cree que armonizar ambos principios es posible, cosa que intentarán las teorías contractualistas. Para Ortega, como estamos señalando, no hay conciliación posible en la práctica, hay tensión, pero, entiéndase bien esto, tal cosa no implica un estado permanente de conflicto violento, sino un nutrido, aunque no ilimitado, conjunto de maneras de estar el individuo en sociedad, aunque siempre «extraño» a ella.

${ }^{16}$ Véase al respecto su famosa conferencia en el Ateneo de París en Febrero de 1819, bajo el título «De la libertad de los antiguos comparada con la de los modernos» (Constant, 1989).
} 
poderosos [...]. En el mundo moderno, la extensión cada vez mayor de las comunidades políticas y, sobre todo, la separación de la autoridad espiritual de la temporal (colocando la dirección de la conciencia del hombre en manos diferentes de las que controlan sus asuntos mundanos), impidieron una intervención grande de la ley en los detalles de la vida privada (Mill, 1979, pp. 41-42).

Si nos guiamos por los mencionados estudios de R. von Ihering, que Ortega toma en consideración, diremos que, al menos para la república romana, no es exacto delinear un poder público dedicado a una permanente «reglamentación» de todas las conductas, sencillamente porque no lo necesitaba. En Roma la ley deja ciertos espacios libres de coacción sobre el individuo, pero sucede que esos espacios están regulados por una moral que sin ser ley deriva de un orden superior ${ }^{17}$. Otra cosa es que desde perspectivas como la de Mill a eso no se le pueda llamar libertad «auténtica» (aunque el romano se «sintiera» libre) ${ }^{18}$. Viene a fijar el autor inglés el cambio de tendencia que permite hablar de un ámbito

${ }^{17}$ Llega a decir Ortega sobre la obra de Ihering, Espiritu del derecho romano, que es «una de las obras gigantescas del siglo pasado que no conocen las nuevas generaciones» (IX, 92). En esta obra aparece precisamente la idea, tan cara a nuestro autor, de que «para los romanos, el derecho no lo era porque fuese ley, sino que la ley lo era porque era derecho» (Ihering, 2005, p. 131). Además puntualiza Ihering (2005) que "para los romanos la libertad no era cosa subjetiva, un bien o una cualidad de la persona, sino una propiedad objetiva, indestructible e inseparable de la voluntad personal perteneciente a las instituciones jurídicas, cada una de las cuales es la expresión de una necesidad o de una finalidad determinada de la libertad. La libertad abstracta encuentra en las instituciones su medida y sus límites y todo acto que contradice el fin de la institución es nulo e improcedente» (p. 160). Con esta inspiración puede decir Ortega que Roma fue uno de los pueblos que vivió en cierta época una «vida como libertad» porque logró adaptar «el Estado a sus preferencias vitales» (VI, 89).

${ }^{18}$ Parece haber una idea de libertad en el autor inglés que excluye a las repúblicas de la antigüedad, presente en fragmentos como los siguientes: «El despotismo es un modo legítimo de gobierno, cuando los gobernados están todavía por civilizar, siempre que el fin propuesto sea su progreso y que los medios justifiquen al atender realmente este fin. La libertad, como principio, no tiene aplicación a ningún estado de cosas anterior al momento en que la especie humana es capaz de mejorar sus propias condiciones por medio de una libre y equitativa discusión» (Mill, 1979, p. 39) y «la única libertad que merece este nombre es la de buscar nuestro propio bien a nuestra propia manera, en tanto que no intentamos privar de sus bienes a otros o frenar sus esfuerzos para obtenerla. Cada cual es el mejor guardián de su propia salud, sea física, mental o espiritual» (Mill, 1979, p. 40). Sin embargo, no deja de reconocer algunos atisbos de libertad limitada a ciertos grupos de individuos: «La lucha entre libertad y autoridad es el rasgo más saliente de aquellas partes de la Historia que nos son familiares, especialmente en las de Grecia, Roma e Inglaterra. Pero, en aquellos tiempos, la disputa se producía entre los individuos, o determinadas clases de individuos, y el gobierno. Se entendía por libertad la protección contra la tiranía de los gobernantes políticos» (Mill, 1979, p. 31). 
privado lejos de la intervención estatal en el momento en que poder «temporal» y «espiritual»se separan. Encontramos aquí semejanza el tema del abandono progresivo de la creencia religiosa que se lleva a cabo en la modernidad, de donde surge la preocupación, que comparte Ortega con Rostovtzeff, por mantener cohesionada una sociedad sin contar con la creencia religiosa-cuya capacidad para llevar a cabo tal tarea es corroborada ampliamente por la historia- lo que implica conservar unas minorías "excelentes» susceptibles de elevar culturalmente a las masas en la medida de lo posible ${ }^{19}$. Además en Ortega el momento creador de las libertades liberales viene dado por una forma de vida, la del «germanomedieval», determinada por una cierta circunstancia socio-histórica. Podremos decir entonces que lo que impidió una «intervención grande de la ley en los asuntos privados» fue el castillo construido por el noble para defenderse del monarca. Incluso este punto de vista permite sostener que posteriormente se produjo un progresivo proceso de abstracción que nos dejó sólo la idea «pura» segregando su posible origen $«$ vital $»^{20}$.

Mill (1979) se sitúa en este momento de abstracción y observa ciertas libertades que hay que defender, las razones que da se mueven en el terreno de lo pragmático y buscarán mostrarnos que si son buenas para el individuo lo son

Lo cual es explicable desde una idea de la «humanidad» como una totalidad capaz de un progresar conjuntamente (entre los antiguos estaría «germinando» ese tipo de libertad).

${ }^{19}$ En efecto, todas estas inquietudes aparecen bien reflejadas en una cita directa que Ortega hace de M. Rostovtzeff, sacada de la obra de 1926, The social and economic history of the roman Empire, en la que subraya que la evolución del mundo antiguo «encierra una lección y una advertencia para nosotros. [...] ¿Es posible extender una civilización superior a las clases inferiores sin rebajar su nivel y diluir hasta desvanecerlas sus cualidades? ¿No está condenada toda civilización a decaer tan pronto como penetran las masas?» (II, 723; Revés de almanaque, 1930). (Véase en la obra original de M. Rostovtzeff, 1998, pp. 540-541). Este, más que «tema de nuestro tiempo", se podría considerar tema de todo tiempo.

${ }^{20}$ Mill (1979) también se da perfecta cuenta de la necesidad de ciertas minorías "creadoras» de «usos» o "descubridoras de verdades» para que avance la sociedad, como ejemplo el siguiente párrafo: "Nadie negará que la originalidad constituye un elemento precioso entre los asuntos humanos. No sólo hay necesidad de gentes que descubran nuevas verdades, o que señalen el momento preciso en que lo que fue largo tiempo una verdad dejó de serlo, sino también de otras personas que den origen a nuevos usos y que den el ejemplo de una conducta más ilustrada, de mejor gusto, y de buen sentido en todas las cuestiones que se puedan presentar. Es cierto que no todos son capaces de obtener tal ventaja. Pocas personas hay, en comparación con toda la especie humana, cuyas experiencias, en caso de ser adoptadas de modo general, sean aptas para producir algún progreso sobre el uso establecido. Pero estas pocas personas constituyen la sal de la tierra. Sin ellas, la vida humana llegaría a convertirse en una poza estancada» (p. 89). La diferencia con Ortega estará entonces en los presupuestos desde los que parte el autor inglés, que determinan el paradigma de «excelencia». 
también para la sociedad. Por ejemplo en su defensa de la libertad de opinión el autor inglés nos dice que

en primer lugar, la opinión que se intenta suprimir por la autoridad muy bien puede ser verdadera; los que desean suprimirla niegan naturalmente, su veracidad pero no son infalibles. No tienen ninguna autoridad para decidir la cuestión por todo el género humano y para impedir a otros el derecho a juzgar. No dejar conocer una opinión, porque se está seguro de su falsedad, es como afirmar que la propia certeza es la certeza absoluta (pp. 46-47).

Ahora bien, el problema es cómo saber si la opinión es "verdadera». El siguiente extracto nos da una posible respuesta, a saber:

Marco Aurelio [...] dueño de todas las conquistas precedentes de la humanidad, dotado de una inteligencia abierta y libre y de un carácter que le condujo a incorporar a sus escritos morales el ideal cristiano, no vio, sin embargo, que el cristianismo, con sus deberes, con los cuales él se sentía tan profundamente identificado, era un bien y no un mal para el mundo (Mill, 1979, p. 54).

En general verdadero será lo que resulta más útil para un supuesto género humano y, a su vez, útil significará que supone un progreso, una mejora. El cristianismo en este caso sería más «verdadero» que la religión del imperio romano porque da lugar a un mundo mejor a ojos del autor inglés, para el que no está escrito que la verdad deba prevalecer por algún tipo de designio divino, pues

los hombres no guardan la verdad con más celo que el error; y una aplicación suficiente de sanciones jurídicas, o incluso sociales, bastará para detener su propagación. La única ventaja que posee la verdad consiste en que, cuando una opinión es verdadera, aunque haya sido reprimida múltiples veces, siempre habrá alguien en el transcurso de los siglos para descubrirla de nuevo, hasta que una de sus reapariciones ocurra en una época en que, por circunstancias favorables, escape a la persecución, al menos durante el tiempo preciso para adquirir fuerza de poder resistir a los ataques posteriores (Mill, 1979, p. 56).

La libre expresión de opiniones incrementaría las posibilidades de sacar a la luz una «verdad» que, según aparece nombrada en este párrafo, atravesaría la historia inmutable pudiendo permanecer oculta hasta ser descubierta por una sociedad que reúna las características adecuadas. Además, la necesidad de un intercambio libre y permanente de opiniones viene dada por la extraordinaria 
complejidad de las verdades en lo que se refiere a asuntos, digamos, espirituales, esto lleva a Mill (1979) a hacer la siguiente distinción:

La peculiaridad de la evidencia de las verdades matemáticas consiste en que los argumentos son unilaterales. No existen objeciones a ellas ni tampoco respuestas a tales objeciones. Pero en todo tema en que la diferencia de opinión es posible, la verdad depende de un equilibrio a guardar entre dos sistemas de razones contradictorias. [...] Pero si pasamos ahora a asuntos infinitamente más complicados -morales, religiosos, políticos, relaciones sociales, de la vida misma-, las tres cuartas partes de los argumentos expuestos en favor de cada opinión discutida consisten en destruir las apariencias que favorecen la opinión contraria (p. 63).

En este sentido, podemos considerar las verdades matemáticas más bien como relaciones necesarias que una vez descubiertas se separan del ámbito de lo opinable, no sucede así con asuntos heterogéneos, que tienen que ver con el mundo del espíritu, de gran complejidad. Esta enorme dificultad para alcanzar una verdad evidente sería otra razón a favor de la necesidad de abrir la puerta a la interacción de opiniones y argumentaciones diversas. Sin embargo, a pesar de esta dificultad Mill (1979) parece creer que en este tipo de asuntos sí se pueden alcanzar verdades «cerradas» por así decirlo, dicho con sus palabras:

A medida que la humanidad progresa, el número de las doctrinas que no son ya objeto de discusión, ni de duda aumenta constantemente, y el bienestar de la humanidad puede medirse casi en relación al número y a la importancia de las verdades que llegaron a ser indiscutibles (p. 69).

Hay por tanto, para el autor inglés, un progreso de la humanidad y hay verdades indiscutibles que están precisamente ligadas a él. El proceso de discusión se hace aquí imprescindible, como decimos, para llegar a verdades en asuntos tan complejos, pues

incluso en el caso en que la opinión recibida de otras generaciones contuviera la verdad y toda la verdad, si no puede ser discutida vigorosa y lealmente, se la profesará como una especie de prejuicio, sin comprender o sentir sus fundamentos racionales (Mill, 1979, p. 77).

Obsérvese el estrecho vínculo que cuidadosamente va tejiendo Mill entre el progreso de la humanidad y el incremento de doctrinas verdaderas, que lo son porque son indiscutibles. Así, la existencia de doctrinas «indiscutibles» en 
todo tiempo se sostiene en una determinada "fe» en el progreso, donde hay una «humanidad», representada por la sociedad inglesa o en general europea, en la que Mill está inmerso, que avanza linealmente de manera que la situación presente siempre resulta mejor que la anterior, pues a pesar de que al autor inglés no se le escapa que existe la posibilidad de que la «verdad» pueda ser reprimida en determinadas épocas y que no hay nada que garantice que salga a la luz, lo que parece subyacer a sus argumentaciones es la creencia de que su propia civilización se encuentra en condiciones de llevar a cabo un proceso de mejora continuo. Desde un punto de vista orteguiano la introducción de ciclos de ascenso y decadencia en las civilizaciones bloquea este exceso de optimismo. En efecto, estudiando con atención la historia nos damos cuenta de que todas las grandes civilizaciones han pasado por un momento de esplendor para luego perecer, este extremo hace ardua la tarea de encontrar argumentos para mantener la esperanza de que una civilización aquejada de todos los síntomas de la decadencia, como es para Ortega la europea, consiga escapar de su fatal destino $^{21}$. En este sentido Ortega llega a hacer suya la preocupación de Mill

por la homogeneidad de mala clase que veía crecer en todo Occidente. Esto le hace acogerse a un gran pensamiento emitido por Humboldt en su juventud. Para que lo humano se enriquezca, se consolide y se perfeccione es necesario, según Humboldt, que exista "variedad de situaciones» ${ }^{22}$. Dentro de cada nación, y tomando en conjunto las naciones, es preciso que se den circunstancias diferentes. Así, al fallar una quedan otras posibilidades abiertas. Es insensato poner la vida europea a una sola carta [...] (IV, 128).

Pero mientras Ortega habla de la «insensatez» de apostar por un sólo tipo de vida, Mill (1979) nos habla de que "puesto que es útil, mientras dure la imperfección del género humano, que existan opiniones diferentes, del mismo modo será conveniente que haya diferentes maneras de vivir» (p. 82). No abandona por tanto el autor inglés ese sesgo "progresista» según podemos observar a la luz de citas como esta, pues parece considerar que esta deseable variedad de formas de vida es algo transitorio que durará «mientras dure la

\footnotetext{
${ }^{21}$ En Sobre la muerte de Roma (1926) señala Ortega que «las causas internas de toda gran decadencia histórica no son más que esto: las limitaciones nativas, iniciales. Cada raza ha llegado al área histórica con su destino preformado, su curva prescrita, y no ha habido manera de reformar su trayectoria. [...] Este es hoy el problema de Europa en general, y de España en particular. [...] Vemos hoy con suficiente claridad que la civilización antigua pudo salvarse» (II, 545-546).

${ }^{22}$ Véase Mill, 1979, p. 83.
} 
imperfección del género humano», es decir, el continuo perfeccionamiento del hombre desembocará algún día en un sólo tipo de vida, que será la que mayor bienestar proporcione al sujeto y por extensión a la sociedad, llegando a una homogeneidad definitiva (que ahora se presenta como beneficiosa para el cuerpo social).

Ortega como máximo podrá decir que el individuo al abrirse a una dimensión personal se encuentra como obligado a construir su propio proyecto de vida genuino e intransferible ${ }^{23}$. Luego puede suceder que se produzca una confluencia de proyectos individuales que quizás puedan derivar en otros proyectos de mayor amplitud y calado social. Forzando un poco la interpretación de lo dicho por Mill, podemos distinguir entre una homogeneidad "mala», a la que se refiere Ortega en la cita de más arriba, y una homogeneidad «buena» que es la que hemos deducido nosotros a partir de lo señalado por el autor inglés. Este último tipo de homogeneidad beneficiosa se podría entender como el estadio en el que todos los individuos de una sociedad han alcanzado la dimensión personal y son capaces de elegir su propia trayectoria vital, su vocación de forma independiente, con lo que su modo de relacionarse se asemejará mucho a los «pactos» de los «señores germanos medievales» que describimos más arriba. No obstante un tipo de sociedad así habría que definirla más bien como homogénea dentro de la pluralidad (algo similar a lo que quiere Ortega para Europa). De lo que no cabe duda es de que el autor inglés considera la conducta de «carácter personal [...] el ingrediente más importante, sin duda, del progreso individual y social» y por eso se queja de que «desgraciadamente, a la espontaneidad individual, no se le suele conceder [...] ningún valor intrínseco»; otra cosa es qué entienda éste por llevar una vida "personal» ${ }^{24}$.

\footnotetext{
${ }^{23}$ Se podría decir que la cuestión central aquí, para la salvación de Europa, es la que se plantea en el «Prólogo para franceses» (1937) de la Rebelión de las masas cuando se pregunta si «pueden las masas, aunque quisieran, despertar a la vida personal, [pues] acaso la estructura de la vida en nuestra época impide superlativamente que el hombre pueda vivir como persona» (IV, 132).

${ }^{24}$ Sin poder entrar más a fondo en la cuestión, digamos que Mill parte de la abstracción de la conciencia para delinear su idea de persona mientras que Ortega parte de la vida humana, del hombre que se las tiene que ver con el mundo.
} 


\section{Conclusiones}

Digamos que el filósofo madrileño desde su paradigma de la razón «histórica» lleva a cabo una conveniente corrección del ingenuo sesgo progresista que trasparece por doquier en las páginas de Mill y ańade al paradigma del individuo autónomo dotado de una conciencia absoluta de raíces kantianas el del «señor germano-medieval», al que hay que volver la vista en su condición de forma de vida creadora de las libertades del liberalismo con el fin de equilibrar y dinamizar el anquilosamiento de las libertades formales hijas de la razón "pura».

En todo caso Ortega no dejará de valorar las aportaciones de estos liberales decimonónicos, pero aunque piense «desde ellos» lo hace para superarlos. Hay de hecho en Mill (1979) críticas similares a las que nuestro autor formulará más tarde en torno a la sociedad europea, por ejemplo la siguiente:

En política resulta casi una trivialidad decir que la opinión pública es la que gobierna al mundo. El único poder que merece este nombre es el de las masas, o el de los gobiernos que se hacen órgano de las tendencias e instintos de las masas. [...] Esas opiniones que se acostumbran a llamar opinión pública no siempre constituyen la opinión de una misma clase de público. En Norteamérica está compuesta por toda la población blanca; en Inglaterra, principalmente por la clase media. Pero siempre por una masa; es decir, una mediocridad colectiva (pp. 90-91).

Sin duda las creencias, estructuradas de diversos modos que arraigan en el pueblo, configuran esa opinión pública de la que habla el autor inglés y condicionan el devenir histórico de la sociedad; no hace falta decir que ese gobierno que se hace órgano de las masas tiene todas las características de un totalitarismo democrático como el que denuncia Ortega en obras como Democracia morbosa. Esto nos lleva a la cuestión clásica de la relación conflictiva de los «mejores», que también para Mill (1979) se caracterizan por su prominente dimensión personal, con la masa; aunque desgraciadamente «la orientación actual de la opinión pública se dirige de modo singular hacia la intolerancia frente a toda demostración clara de individualidad» (p. 93). Asimismo éste nos habla de un "principio progresista» que «es siempre enemigo del imperio de la costumbre», de hecho "la mayor parte de los países del mundo carecen de historia, propiamente hablando, porque el despotismo de la costumbre es completo" (Mill, 1979, p. 95). La idea de progreso de la que parte el inglés le impide valorar en su justa medida la importancia de la tradición, de la historia 
que tenemos a nuestras espaldas, aunque le pone en disposición de exaltar la diversidad europea, así se pregunta: "¿qué es lo que ha hecho de la familia de naciones europeas una porción progresista y no estacionaria de la humanidad? [...] Su notable diversidad de carácter y de cultura» (Mill, 1979, p. 96). De aquí salta a quejarse de la señalada homogeneidad de la sociedad de su tiempo, de una forma que sin duda recuerda a algunos pasajes de La rebelión de las masas:

Ahora, de un modo relativo, claro está, todos ven, leen, escuchan las mismas cosas, y van también a los mismos lugares; tienen sus esperanzas y temores dirigidos a los mismos objetivos, tienen los mismos derechos, las mismas libertades y los mismos medios de reivindicarlos (Mill, 1979, p. 97).

Por otro lado, respecto a la cuestión de «los límites de la autoridad de la sociedad sobre el individuo», Mill (1979) considera que «la individualidad debe gobernar aquella parte de la vida que interesa principalmente al individuo, y la sociedad la parte que interesa principalmente a la sociedad» (p. 99). Pero la cuestión, como se ha indicado, es discernir qué parte corresponde a cada ámbito, pues si queremos salir del ámbito psicológico que supone que cualquiera puede sentirse perjudicado por la conducta individual de otro sujeto, aunque aparentemente no haya motivos para la queja, tendremos que buscar una instancia objetiva que decida sobre la cuestión, ya sean unas normas morales vigentes en la sociedad o un derecho incluido en una institución estatal, esto nos aboca a la necesidad de tener en cuenta la costumbre, la tradición, como instancia que garantiza la estabilidad social. En otras palabras, en una sociedad "progresiva», enteramente volcada hacia el futuro, como la que se adivina en los planteamientos de Mill, los criterios objetivos o intersubjetivos para distinguir cuándo estamos ante un perjuicio de los intereses del otro o ante una invasión de lo privado por parte de lo público corren el riesgo de terminar diluyéndose. Se diría que en el autor inglés la preocupación por esa concordia básica que señalaba Ortega, inspirado en Cicerón, no existe, ya que se da por hecha, es por naturaleza. Por el contrario, la circunstancia histórica en la que se ve envuelto el filósofo español le hace ver, en parte, la necesidad de cuidar esa concordia-que se expresa en las "creencias» en sentido objetivo que señalábamos-, de mantenerla y tratar de rehacerla en su caso, pues está sujeta a las vicisitudes de la historia. En efecto, el «suelo» sobre el que se sustenta la cohesión social no es tan sólido como los liberales decimonónicos pensaban, las sociedades son susceptibles de entrar en crisis que amenazan su supervivencia, nada nos asegura un progreso continuado, y en ese caso hay que volver a construir vigencias para sostenerlas. Esto es precisamente lo que observamos en la antigua Roma, a la que Ortega 
se refiere constantemente a la hora de diagnosticar los males de la sociedad española y europea. Todo ello atravesado por una concepción de la libertad individual que no parte del sujeto autónomo sino que encuentra su inspiración en el germano medieval. La idea es conectar la libertad real que vive cada cual con la libertad política. Para moldear ésta desde aquélla. Para ello hacen falta individuos que hayan «despertado» a la vida personal.

\section{Bibliografía}

Aron, R. (2006). «Una lectura crítica de "La rebelión de las masas"». Revista de estudios orteguianos, $\mathrm{n}^{\circ} 12 / 13$, noviembre, pp. 231-242.

BLoch, M. (2011). La sociedad feudal. Madrid: Akal.

Cicerón (1991). Sobre la república. Introducción, edición y notas de D’Ors A. Madrid: Gredos.

Constant, B. (1989). «Principios de política». En Escritos políticos. Madrid: Centro de estudios constitucionales, pp. 257-285.

Fromm, E. (2005). El miedo a la libertad. Buenos Aires: Paidós.

Gray, J. (1994). Liberalismo. Madrid: Alianza editorial.

Ihering, R. von. (2005). El espiritu del Derecho romano. Abreviatura por Vela F., prólogo Hernández Marín, R. Madrid: Marcial Pons.

López Frías, F. (1992). «La recepción del utilitarismo en el mundo hispánico. El caso de Ortega y Gasset». Revista Iberoamericana de estudios utilitaristas, vol. $1 \mathrm{n}^{\circ} 3$. pp. 111-144.

Mill, J. S. (1977). «De Tocqueville on Democracy in America, [I], [II]». En Robson, J. M., (Ed.), Brady A., (Introducción), Collected Works of John Stuart Mill, Volume XVIII, Essays on Politics and Society. Toronto: University of Toronto, pp. 47-204.

Mill, J. S. (1979). «Sobre la libertad». En Sobre la libertad. Capitulos sobre el socialismo y otros escritos. Barcelona: Ediciones Orbis, pp. 27-138.

Ortega y Gasset, J. (1966). Obras Completas, tomo I. Madrid: Revista de Occidente.

- (1963). Obras Completas, tomo II. Madrid: Revista de Occidente.

- (1966). Obras Completas, tomo III. Madrid: Revista de Occidente.

- (1966). Obras Completas, tomo IV. Madrid: Revista de Occidente.

- (1964). Obras Completas, tomo V. Madrid: Revista de Occidente.

- (1964). Obras Completas, tomo VI. Madrid: Revista de Occidente. 
- (1964). Obras Completas, tomo VII. Madrid: Revista de Occidente.

- (1965). Obras Completas, tomo VIII. Madrid: Revista de Occidente.

- (1965). Obras Completas, tomo IX. Madrid: Revista de Occidente.

- (1988). Obras Completas, tomo XI. Madrid: Alianza/ Revista de Occidente.

- (1988). Obras Completas, tomo XII. Madrid: Alianza/ Revista de Occidente.

- (1994). Obras Completas, tomo X. Madrid: Alianza/ Revista de Occidente.

Rodríguez HuÉscar, A. (1979). Introducción a Sobre la libertad de Mill, J. S. En Sobre la libertad. Capitulos sobre el socialismo y otros escritos. Barcelona: Ediciones Orbis, pp. 15-25.

Rostovtzeff, M. (1998). The Social and Economic History of the Roman Empire. 2 vols., $2^{\text {a }}$ edición revisada por Fraser P. M. New York: Oxford University Press Inc.

Recibido: 29/03/2016

Aceptado: 17/03/2017

ENDOXA está bajo una licencia de Creative Commons Reconocimiento-NoComercial-SinObraDerivada 4.0 Internacional 
